ARTICLE

https://doi.org/10.1038/s41467-019-08606-2

\title{
Enhanced North Pacific deep-ocean stratification by stronger intermediate water formation during Heinrich Stadial 1
}

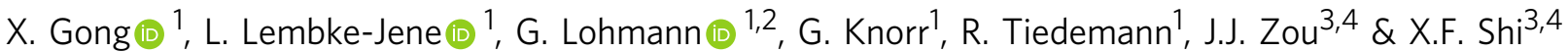

\begin{abstract}
The deglacial history of $\mathrm{CO}_{2}$ release from the deep North Pacific remains unresolved. This is due to conflicting indications about subarctic Pacific ventilation changes based on various marine proxies, especially for Heinrich Stadial 1 (HS-1) when a rapid atmospheric $\mathrm{CO}_{2}$ rise occurs. Here, we use a complex Earth System Model to investigate the deglacial North Pacific overturning and its control on ocean stratification. Our results show an enhanced intermediate-to-deep ocean stratification coeval with intensified North Pacific Intermediate Water (NPIW) formation during HS-1, compared to the Last Glacial Maximum. The stronger NPIW formation causes lower salinities and higher temperatures at intermediate depths. By lowering NPIW densities, this enlarges vertical density gradient and thus enhances intermediate-to-deep ocean stratification during HS-1. Physically, this process prevents the North Pacific deep waters from a better communication with the upper oceans, thus prolongs the existing isolation of glacial Pacific abyssal carbons during HS-1.
\end{abstract}

\footnotetext{
${ }^{1}$ Alfred-Wegener-Institut Helmholtz-Zentrum für Polar- und Meeresforschung, Bussestr. 24, 27570 Bremerhaven, Germany. ${ }^{2}$ MARUM-Center for Marine Environmental Sciences, University Bremen, Leobener Strasse, 28359 Bremen, Germany. ${ }^{3}$ Laboratory for Marine Geology, Qingdao National Laboratory for Marine Science and Technology, Qingdao 266061, China. ${ }^{4}$ Key Laboratory of Marine Sedimentology and Environmental Geology, First Institute of Oceanography, Ministry of Natural Resources, Qingdao 266061, China. Correspondence and requests for materials should be addressed to X.G. (email: GongXun.Allen@awi.de)
} 
T he last deglacial atmospheric $\mathrm{CO}_{2}$ rise has been attributed to the release of deep, sequestered carbon out of the global ocean, likely linked to abrupt, millennial-scale changes of the Atlantic Meridional Overturning Circulation $(\mathrm{AMOC})^{1}$. In particular, the rapid atmospheric $\mathrm{CO}_{2}$ rise during the AMOC offmode in Heinrich Stadial 1 (HS-1, 17.5-14.9 ka) is thought to be mainly induced by the $\mathrm{CO}_{2}$ outgassing from the Southern Ocean $^{2-5}$ and a lower efficiency of the biological carbon pump globally ${ }^{6,7}$. In parallel, studies have indicated a large storage of dissolved inorganic carbon (DIC) in the North Pacific deep waters (NPDW, the water mass below $\sim 2500 \mathrm{~m}$ depth) during the Last Glacial Maximum (LGM, 23-18 ka) ${ }^{8}$. However, studies based on various marine proxies gave contradicting evidence that deepocean carbon was released from the North Pacific during HS-1 or, in contrast, remained isolated in a deep marine reservoir ${ }^{8-13}$. Specifically, such conflicting views revolve around whether or not the subarctic Pacific ventilation in HS-1 became deep and intense enough to connect to the deep ocean ${ }^{9,14,15}$. Once convection down to the deep ocean is established, the subarctic Pacific ventilation will be able to exchange properties, such as deepocean DIC, into intermediate depths, and then ventilate to the surface ocean for a potential $\mathrm{CO}_{2}$ release. Thus, the abrupt change of deglacial subarctic Pacific ventilation and the corresponding deep-ocean stratification are the two physical characteristics that determine the role of North Pacific Ocean in the global carbon cycle system during the last glacial termination.

Under modern climate conditions, the North Pacific ventilation mainly occurs in the Okhotsk Sea and produces the North Pacific Intermediate Water (NPIW), dominantly controlled by brine rejection during winter sea ice growth ${ }^{16,17}$. Accordingly, paleoceanographic studies have hypothesized a role of potential sea ice expansion in causing a deeper ventilation (Fig. 1a-c) and probably stronger NPIW formation in HS- 1 than during the $\mathrm{LGM}^{15,18-20}$, besides a direct control of a colder surface ocean ${ }^{21}$. In parallel, modelling studies have ascribed the stronger NPIW or NPDW formation of HS-1 to either intensified northward advection of warm, saline waters from the subtropical to the subarctic Pacific Ocean ${ }^{14}$, a removal of the subpolar North Pacific halocline ${ }^{22}$ or a colder and more saline surface subarctic Pacific Ocean during the North Atlantic cold events ${ }^{23,24}$. Nevertheless, a common characteristic of these otherwise partially exclusive explanations involves a breakdown of the surface-ocean density stratification in the subarctic Pacific Ocean. Regarding the maxima depths of deglacial North Pacific ventilation, there is hypothesized overturning throughout intermediate depths and down to the deep ocean of $\sim 3000 \mathrm{~m}^{11,14}$. In contrast, some other studies have argued that the deep-ocean water is decoupled from the mid depths $(\sim 2000 \mathrm{~m})$ and thus a continued isolation of the NPDW during HS-19,15,25,26.

In this study, we use a complex Earth System Model, MaxPlank-Institute Earth System Model (MPI-ESM) 27 (see Methods), to simulate deglacial North Pacific ventilation. Our work aims to complement the limitations of currently available proxy evidence in identifying the paleo-physical mechanisms of the HS-1 intensified North Pacific ventilation and development of North Pacific deep-ocean stratification. Our modelling results provide evidence for stronger NPIW formation during HS-1, triggered by increased surface salinity and strengthened by a positive temperature feedback. In conjunction with paleoceanographic evidence, we suggest an enhanced NPIW-to-NPDW stratification due to stronger NPIW formation during HS-1.

\section{Results}

Enhanced NPIW formation during HS-1. In our HS-1 experiment (see Methods), when the North Atlantic freshwater perturbation (FWP) starts, the AMOC slows down rapidly, while the North Pacific ventilation gradually intensifies (Fig. 1d, e and Supplementary Fig. 1). In the following, we define the averaged state of 301-400 model years as the HS-1 state. It yields a quasiequilibrium state of the substantially weakened AMOC with less than 5 Sverdrup ( $\mathrm{Sv}, 1 \mathrm{~Sv}=10^{6} \mathrm{~m}^{3} \mathrm{~s}^{-1}$ ), in line with the indication by marine proxies ${ }^{28,29}$, and a sustained maximum of NPIW formation with $\sim 3.8 \mathrm{~Sv}$ (see Methods for the calculation of AMOC and NPIW strengths). In parallel, a N-S ocean transect along $180^{\circ} \mathrm{E}$ exhibits significantly lower salinities down to $2300 \mathrm{~m}$ depths, compared to the LGM state (Supplementary Fig. 2). This indicates a stronger NPIW rather than NPDW formation, in line with paleoceanographic evidence ${ }^{9,15}$. Moreover, our simulated LGM and HS-1 states reveal deepened winter (i.e. mean of January, February and March) mixed layer depths (wMLD) in the middle of the Okhotsk and the western Bering Seas, compared to the rest of the subarctic Pacific Ocean and its marginal seas (Figs. 1f, 2c, see Supplementary Fig. 3 for the MLD seasonality change). This marks these two areas as the predominant glacial NPIW source regions in our modelling simulations, corroborating paleoceanographic evidence ${ }^{18,30,31}$.

Our experiments characterize the middle of the Okhotsk and the western Bering Seas by higher sea surface salinities (SSS) and deepened wMLD in HS-1 compared to the LGM state, while the winter sea surface temperatures (SSTs) in the same area are not colder than during the LGM (Figs. 1f, 2a-c). Here, we attribute the stronger NPIW formation of HS-1 to the enhanced convection in the middle of Okhotsk and the western Bering Seas, controlled by a weakened surface halocline superimposed on the cold glacial surface ocean.

In our results, the weakened surface halocline in the middle of the Okhotsk and western Bering Seas correlates with an intensified Aleutian Low-pressure system during HS-1. Once the AMOC weakens, the Aleutian Low intensifies simultaneously (Fig. 3a). This rapid atmospheric teleconnection from the North Atlantic to subarctic Pacific occurs via tropical latitudes with higher SSTs in the Eastern Equatorial Pacific acting as a pivot in the mechanism (Supplementary Fig. 4), as discussed in previous modelling studies ${ }^{24,32}$. Over the mid-latitude North Pacific, the stronger Aleutian Low causes stronger Westerlies and thus accelerates the North Pacific surface circulation (Fig. 3). As a consequence, larger amounts of subtropical-sourced, saline water are transported northwards, leading to the higher SSS in the subarctic Pacific Ocean and its marginal seas (Fig. 2b). Moreover, relative to the LGM, the strengthened Aleutian Low of HS-1 generates an anomalous cyclonic atmospheric circulation over the subarctic Pacific (Fig. 2d). This pattern transports drier air masses from the East Siberian continent to the Okhotsk and western Bering Seas. Such a process acts to additionally increase the SSS of the Okhotsk and western Bering Seas and thus weakens the surface halocline during HS-1 by reducing the regional net precipitation, in line with drier conditions in the Far East region during millennial-scale cold periods of the deglaciation as indicated by terrestrial proxies ${ }^{33,34}$. Furthermore, the anomalous cyclonic atmospheric circulation over the subarctic Pacific of HS1 drives a stronger subarctic Pacific gyre at the AMOC off-mode (Fig. 3b). This results in a stronger upwelling of relatively warmer, more saline water from subsurface depths, by enhancing the Ekman pumping effect. In the surface ocean, the thermal buoyancy of these upwelled subsurface water is counteracted by a heat loss to the cold surface atmosphere; however, the water remains saline and thus further weakens the surface stratification. Overall, our results suggest that the intensified Aleutian Low of HS-1 weakens the surface halocline in the Okhotsk and Bering Seas via multiple processes in the atmosphere-ocean coupled system. Here, our results provide modelling support to previous 


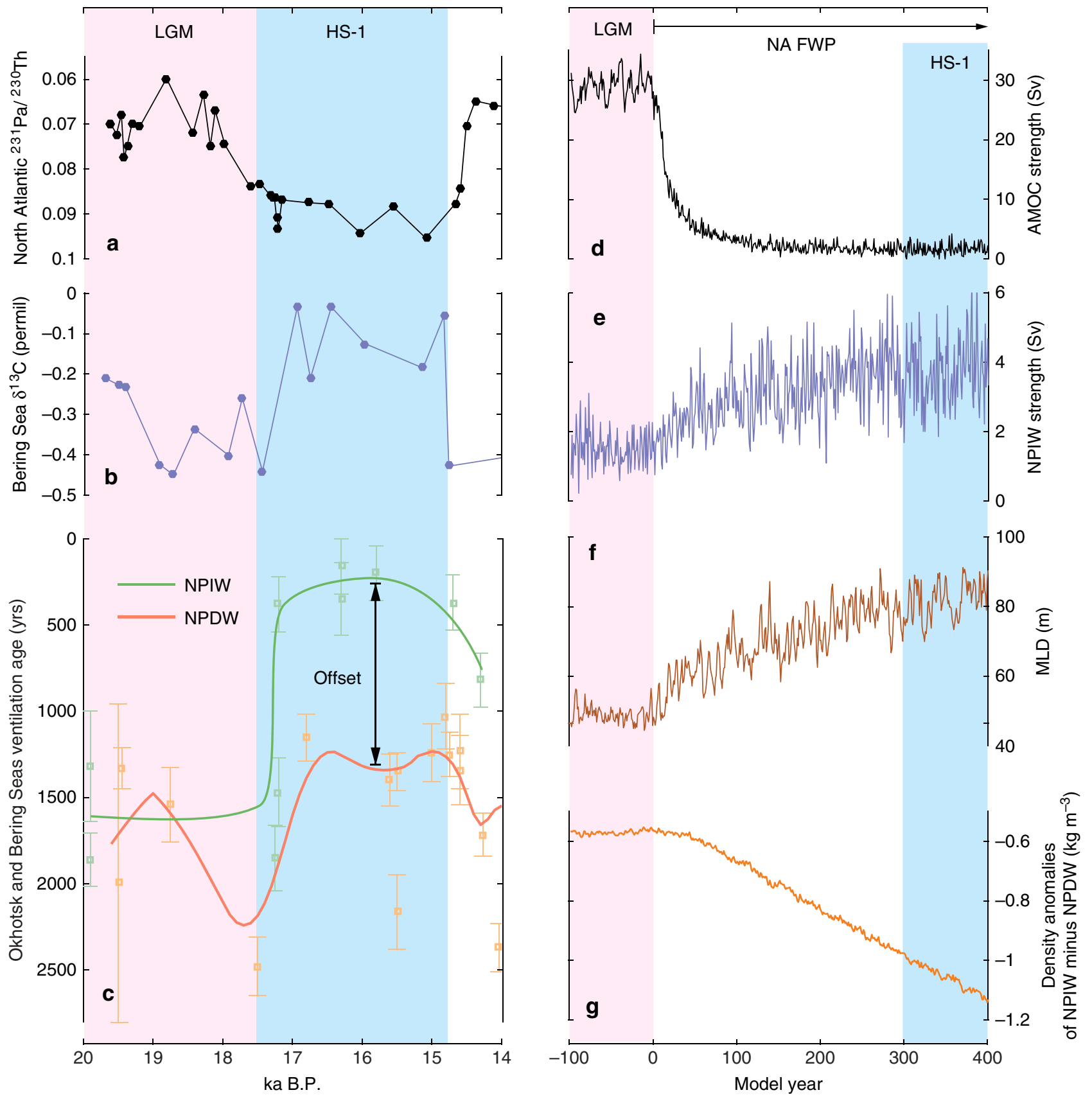

Fig. 1 Collected proxy records and the modelling results in this study. a Reconstructed AMOC change on the basis of sedimentary ${ }^{231} \mathrm{~Pa} /{ }^{230} \mathrm{Th}$ ratio; ${ }^{3}$ b Benthic foraminiferal $\delta^{13} \mathrm{C}$ records at the intermediate depths of the Bering Sea, with higher values for stronger NPIW formation; ${ }^{15}$ c NW Pacific intermediate and deep-ocean ventilation ages, with the error bars from radiocarbon measurements; 15 d Modelled AMOC strengths; e Modelled NPIW strengths; $\mathbf{f}$ Modelled annual mean MLD in the middle of Okhotsk and western Bering seas; $\mathbf{g}$ Modelled subarctic Pacific NPIW (at 1000 m) and NPDW (at $3000 \mathrm{~m}$ ) density anomalies

hypotheses about the effective role of Aleutian Low in changing glacial NPIW formation, beyond earlier broad conceptual assumptions ${ }^{20,35,36}$.

In our results, the stronger convection in the Okhotsk and Bering Seas of HS-1 is initiated when the surface halocline becomes weakened while the SSTs in the same region are below 0 ${ }^{\circ} \mathrm{C}$ and similar to the LGM conditions. Therefore, our results suggest that the presence of a surface-ocean halocline prevents the NPIW from a higher formation during the LGM, although the cold winter SSTs should be conducive to a stronger NPIW production. This resembles the known low-salinity barrier that constrains the modern NPIW formation in the Okhotsk Sea ${ }^{17}$, and is also in line with previous modelling results about the dependence of glacial NPIW formation on the subpolar Pacific stratification $^{37}$. Notably, our simulated stronger NPIW formation in HS-1 occurs on the basis of the continued existence of a halocline between the surface and intermediate ocean since the LGM, although such halocline becomes relatively weaker in HS-1 (Supplementary Fig. 2d-f). At the onset of the stronger NPIW formation during HS-1, the stronger convection transports more surface water with relatively lower salinities down to the intermediate-depth ocean, while it in turn ventilates the relatively more saline water from the intermediate to surface ocean. This process thus works to further weaken the halocline, acting as a 

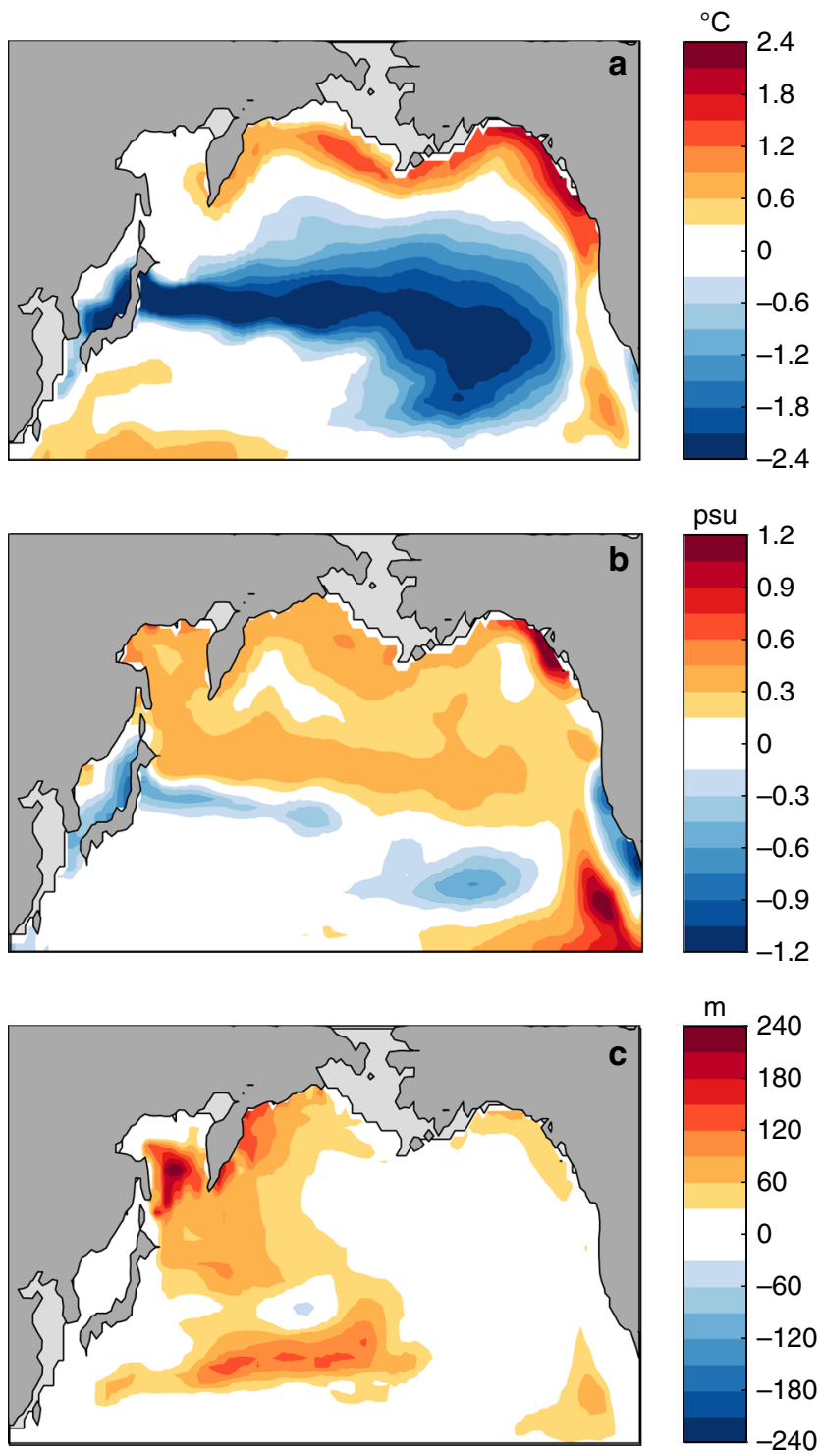

$\mathrm{mm}$ month $^{-1}$
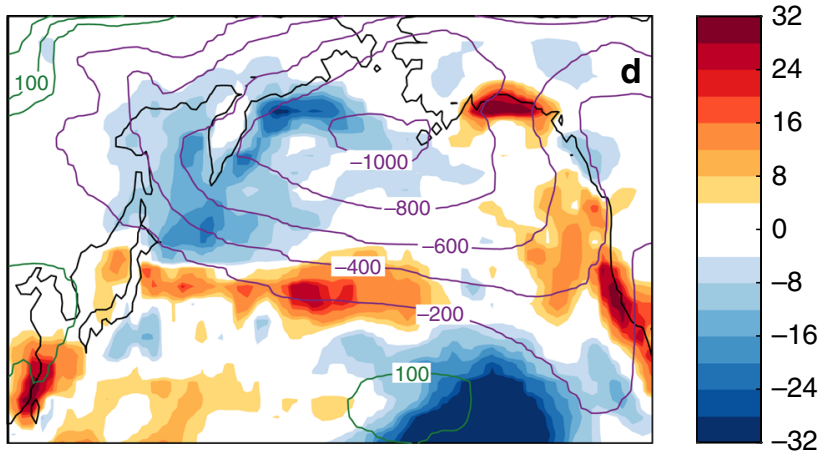

Fig. 2 Modelled North Pacific change due to AMOC slow-down. a Winter SST anomalies of HS-1 to the LGM; b The coeval winter SSS anomalies; c The coeval wMLD anomalies; $\mathbf{d}$ The coeval change in winter atmospheric circulation. In $\mathbf{d}$, the shading colours show net precipitation change, and the green and purple lines describing positive and negative change in sea level pressures, respectively. Here, the negative values of sea level pressure change over the subarctic Pacific Ocean imply an intensified Aleutian Low system in HS-1

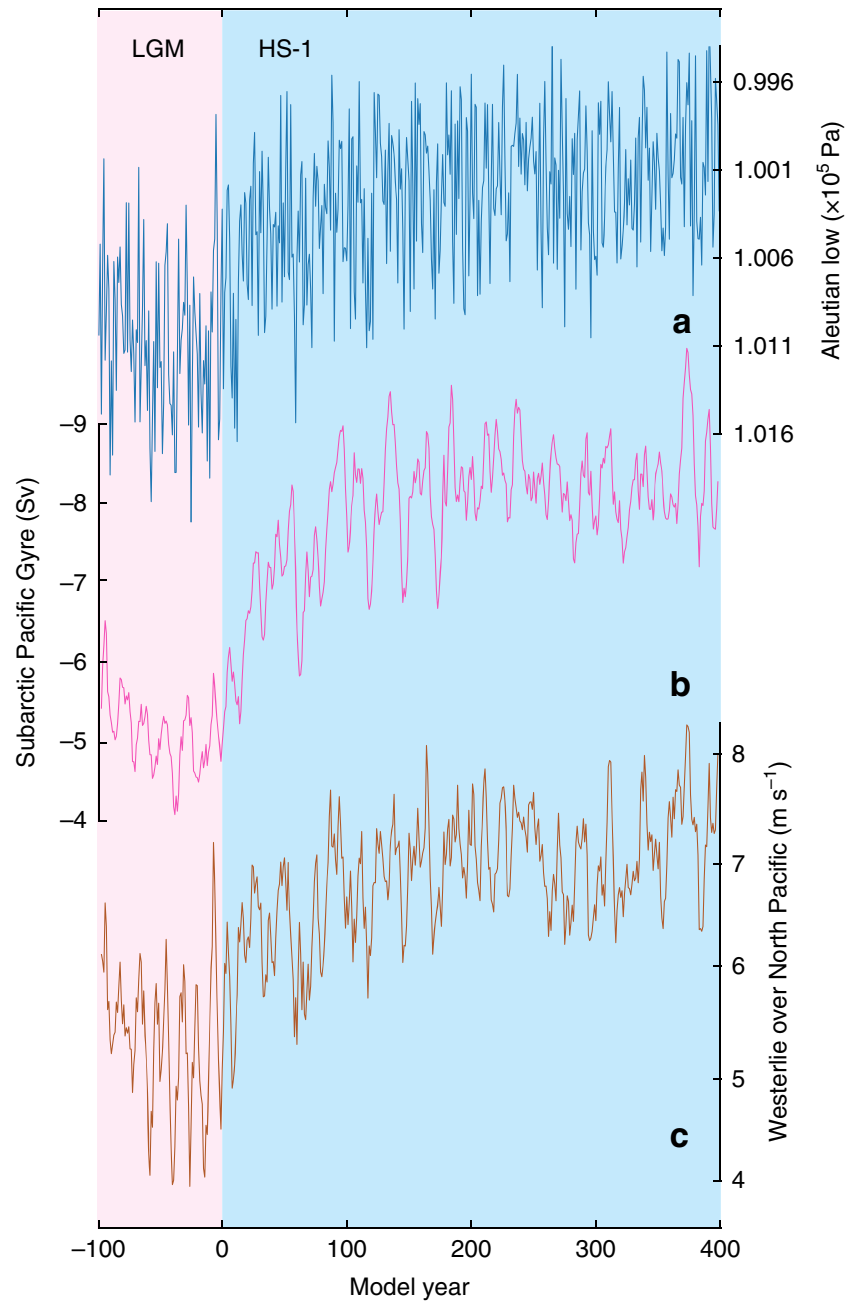

Fig. 3 Modelled surface atmosphere and ocean change in the North Pacific climate system. a Strength of the Aleutian Low, indexed by the regional minima of sea level pressures; b Strength of the subarctic Pacific gyre, indexed by the regional minima in stream functions; $\mathbf{c}$. Strength of the Westerlies averaged between 30 and $50^{\circ} \mathrm{N}$ over the North Pacific Ocean

positive feedback (salinity feedback, thereafter) for the NPIW intensification during HS-1. Here, our results indicate that a weakening, instead of a complete removal ${ }^{22}$, of the surface halocline triggers the stronger NPIW formation during HS-1 in conjunction with cold glacial surface ocean, and is also favoured by the salinity feedback.

Notably, our results show that the stronger northward transport of subtropical-sourced warmer and more saline surface water does not lead to a warmer surface ocean in the NW Pacific and its marginal seas during HS-1 (Fig. 2a), in line with previous paleoceanographic evidences ${ }^{38,39}$. In our results, the absence of a warmer NW Pacific in HS-1 is a result of the competition between atmospheric cooling impact and ocean warming potential. At the AMOC off-mode, the anomalous cyclonic atmospheric circulation of the stronger Aleutian Low transports a larger amount of cold air masses from the East Siberian continent to the Okhotsk and western Bering Seas. This process cools down the regional surface ocean, acting as the atmospheric cooling impact. In parallel, the oceanic warming potential correlates to the stronger northward advection of subtropical warmer water into the high latitudes North Pacific and the upwelling of relatively warmer water from the subsurface layer (due to the stronger ventilation and subarctic Pacific gyre). In the NW Pacific 


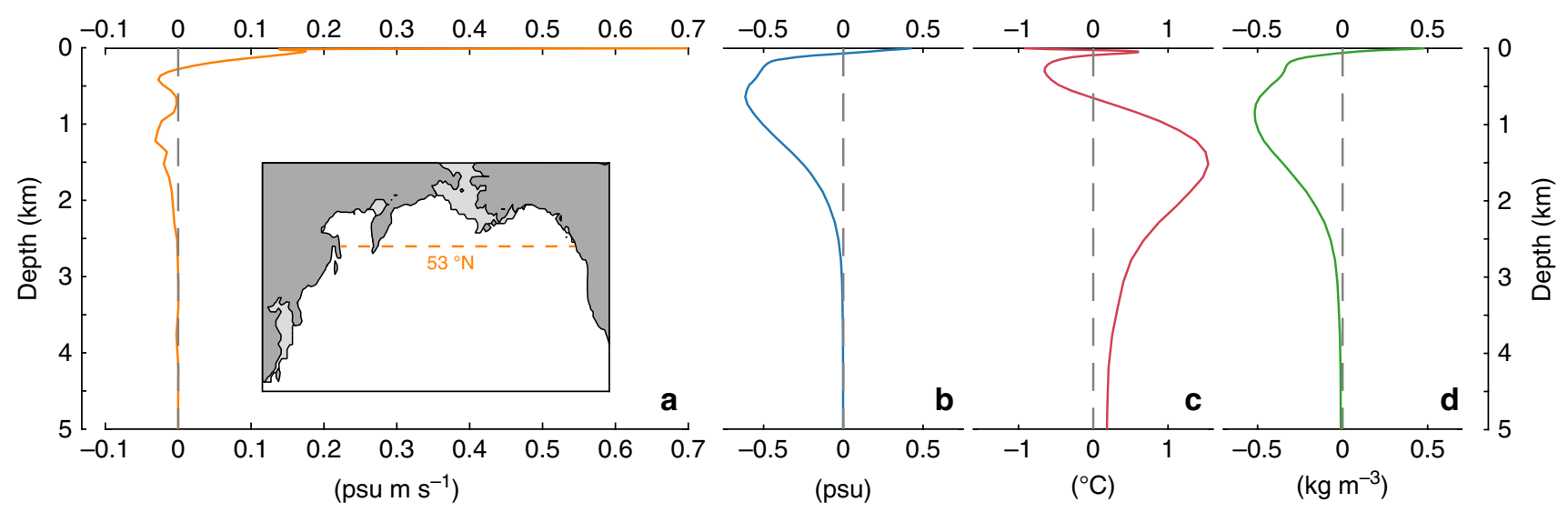

Fig. 4 Modelled anomalies in the vertical profiles of the North Pacific Ocean and its marginal seas. a Northward salt flux averaged at $53^{\circ} \mathrm{N}$ across the entire North Pacific basin. The salt flux is calculated by multiplying salinity and meridional velocity, with the northward flux in positive values (see change in salinities and velocities at $53^{\circ} \mathrm{N}$ in Supplementary Fig. 5). b-d show the anomalies of the salinity, temperature and density averaged in the Okhotsk and west Bering Seas of the modelled HS-1 compared to LGM state, respectively

and its marginal seas, the atmospheric cooling impact and ocean warming potential work to change the SSTs in opposite ways, with their competition results determining the ultimate change in the SSTs from the LGM to HS-1. Here, these two competitive processes have important implication in understanding the distinct behaviours of the Atlantic-Pacific thermal seesaw in previous modelling studies: when the atmospheric cooling impact acts as the dominant control, the North Pacific shows lower SSTs in HS-1 $31,40,41$; while when the ocean warming potential becomes in charge, the subarctic Pacific turns to warmer conditions against the cooling in the North Atlantic at the AMOC off-mode, thus constituting an Atlantic-Pacific thermal seesaw ${ }^{37,42}$. In this study, a case of close contest between the atmospheric cooling impact and oceanic warming potential results in the SSTs of HS- 1 to be overall comparable with the LGM values in the Okhotsk Sea (Fig. 2a). This explains the same climatic signals in the paleo temperature reconstructions from this region ${ }^{38,39}$. Moreover, our modelling results characterize a non-uniform SST change in the vast area of the subarctic Pacific and its marginal seas from the LGM to HS-1. This is attributed to the spatial inconsistence of the competing amounts of the atmospheric cooling impact vs. oceanic warming potential. Here, our mechanism provides a unifying explanation for the regional heterogeneity among the previous paleoceanographic upper-ocean temperature reconstructions in the NW Pacific and its marginal seas ${ }^{36,43}$. In essence, the Atlantic-Pacific thermal seesaw is not a uniform feature of the high latitudes North Pacific in response the AMOC slow-down according to our modelling results, thus regionally decoupling it from the Atlantic-Pacific MOC seesaw ${ }^{42}$.

Enhanced intermediate-to-deep ocean stratification during HS1. Our modelling results characterize the NPIW by lower densities in HS-1 compared to the LGM, meanwhile the NPDW shows only insignificant change (Fig. 4 and Supplementary Fig. 2). This leads to a larger contrast in the vertical density gradients and thus a strengthened NPIW-to-NPDW stratification during HS-1 (Fig. 1g). More specifically, our results reveal that lower densities of NPIW in HS-1 are attributed to its lower salinities and higher temperatures compared to the LGM (Fig. $4 \mathrm{~b}-\mathrm{d}$ ). When the AMOC weakens in our experiment, a stronger halocline between the intermediate and deep ocean develops due to the salinity feedback. This constrains the impact of relatively colder deep ocean water on the intermediate depths by limiting the vertical water exchange, thus retaining the warmer characteristic within NPIW during HS-1 (Fig. 4 and Supplementary Fig. 2). In turn, this process also enhances the deep ocean stratification by enhancing the thermocline between the intermediate and deep ocean, thus creating a positive feedback (temperature feedback, thereafter) in developing an intensified intermediate-to-deep ocean stratification during HS-1.

In our results, the NPIW change from the LGM to HS-1 is characterized not only in the subarctic Pacific, but is also advected southwards via the mid-depth ocean circulation. This thus provides lower salinities and higher temperatures to the lower latitudes (Supplementary Fig. 5). In Fig. $4 \mathrm{a}, \mathrm{W}$-E transect at $53^{\circ} \mathrm{N}$ across the entire North Pacific Ocean shows a stronger-thanLGM southward transport of low-salinity water at intermediate depths during HS-1. This is attributed to the coeval stronger southward ocean flow mainly between 500 and 2000 depths (Supplementary Fig. 5b, f, j), thus it depicts a stronger advection of NPIW to lower-latitude Pacific during HS-1. Along the coast of the Gulf of Alaska, our results characterize a relatively warmer surface ocean, and a warmer and less saline intermediate ocean during HS-1 compared to the LGM (Supplementary Fig. 5d, f). These are in line with previously reported paleoceanographic evidence based on oxygen isotopes from foraminifera in this $\operatorname{area}^{44,45}$.

To assess the sensitivity of our results to the amount of North Atlantic FWP, we also performed additional experiments with a half $(0.4 \mathrm{~Sv})$ or twice $(1.6 \mathrm{~Sv})$ the strength of the freshwater fluxes. In these experiments, our results give the same qualitative results of the enhanced NPIW-to-NPDW stratification along with the stronger NPIW formation under the HS-1 climate conditions (Supplementary Fig. 6). In these two alternate experiments, a stronger North Atlantic FWP indeed leads to stronger NPIW formation and a further development of the NPIW-to-NPDW stratification, due to the correspondingly intensified Aleutian Low (Supplementary Fig. 7). Moreover, a reanalysis of previous modelling results ${ }^{46}$ using a different Earth System Model also suggested a similar connection between the NPIW intensification and NPIW-to-NPDW stratification development at AMOC offmode, although the previous modelling results presented a higher sensitivity to the North Atlantic FWP (Supplementary Fig. 8). Therefore, we demonstrate that the development of North Pacific deep ocean stratification along with stronger NPIW formation is independent from the AMOC slow-down process, as long as the AMOC reaches an off-mode state. Furthermore, we have performed an additional experiment with a stepwise increase in FWP (Supplementary Fig. 9). This experiment shows that the 
a

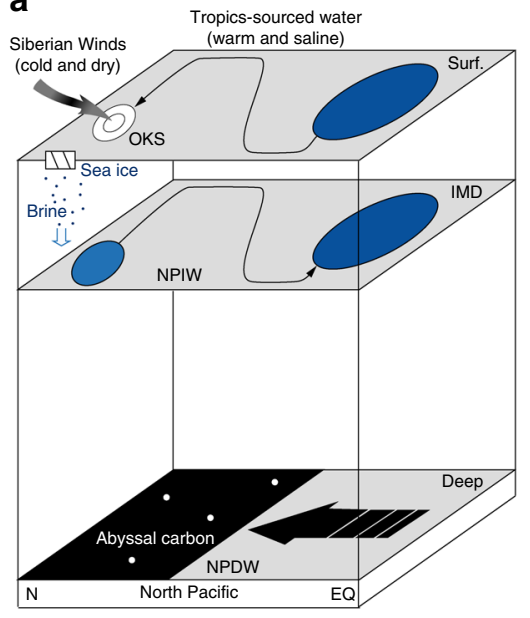

b

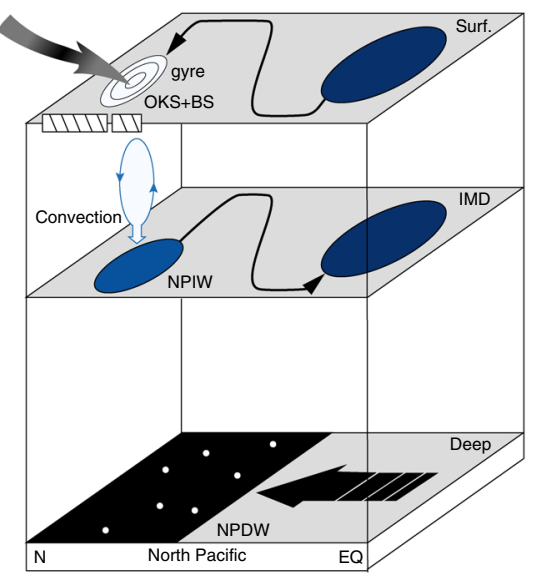

C

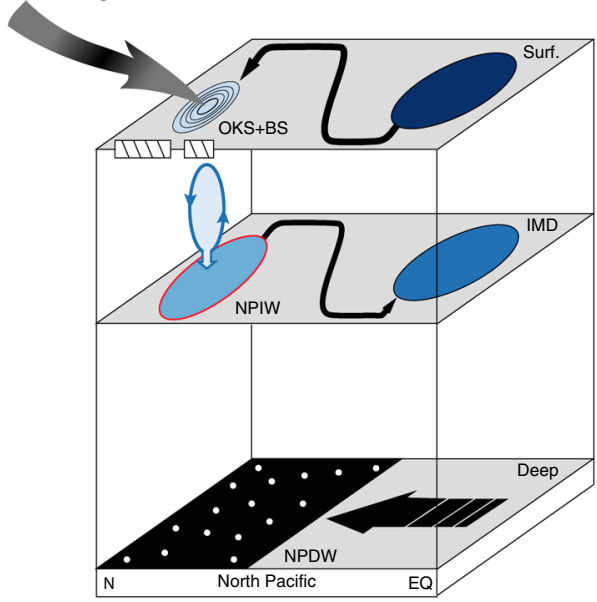

Fresher / less dense

More saline / denser

Fig. 5 Schematic illustration of the mechanism proposed in this study and its implication for the reservation of North Pacific deep-ocean carbon. a The Modern; b LGM and c HS-1. OKS and BS mean the Sea of Okhotsk and Bering Sea, respectively. The white-bluish-black colours indicate an increase in salinities and also densities. In the subarctic Pacific region, denser circles indicate a stronger gyre circulation. In c, the red circle of the NPIW water indicates relatively warmer conditions during HS-1 compared to the LGM conditions

North Pacific responses to the AMOC off-mode is robust for basic LGM AMOC background states that can be weaker or stronger than in our simulated pre-industrial (PI) state. These background strengths are comparable to other estimates for the LGM AMOC states ${ }^{47,48}$, although much weaker basic states ${ }^{49}$ cannot be excluded.

Our North Atlantic FWP experiments apply the LGM level of 193 ppm $\mathrm{CO}_{2}$, thus lower than the recorded HS-1 atmospheric $\mathrm{CO}_{2}$ increase in the ice cores ${ }^{1}$. To avoid an unintended impact of the higher $\mathrm{CO}_{2}$ during $\mathrm{HS}-1$ to our proposed physics, we additionally conducted an experiment applying the $0.8 \mathrm{~Sv}$ FWP together with a 240-ppm atmospheric $\mathrm{CO}_{2}$ concentration. In such experiment, although the NPIW production rate becomes relatively lower than that under the $193 \mathrm{ppm} \mathrm{CO}_{2}$ conditions, it remains significantly stronger than the LGM conditions, while the AMOC also remains in an off-mode of less than $5 \mathrm{~Sv}$ (Supplementary Fig. 6). Thus, we argue that the AMOC slowdown exerts a decisive control on the physical response of the stronger NPIW formation and corresponding intermediate-todeep stratification, aligning with the concept of Atlantic-Pacific MOC seesaw ${ }^{9,15,42}$.

Our deglacial North Atlantic FWP experiments with a complex Earth System Model show a stronger NPIW formation and coeval enhancement of NPIW-to-NPDW stratification during HS-1. In our results, the NPIW formation maxima during HS-1 are attributed to the intensified North Pacific convection in the middle of Okhotsk and western Bering Seas, controlled by a significantly weakened surface halocline in conjunction with cold glacial SSTs and favoured by a salinity feedback. This stronger NPIW formation of HS-1 subducts a large amount of surface relatively less saline water down to the intermediate depths, as schematically illustrated in Fig. 5. This process determines the lower densities of the NPIW during HS-1. In parallel, our results yield no significant changes in NPDW densities from the LGM to HS-1. By enlarging the vertical density gradient, this results in an enhanced NPIW-to-NPDW stratification during HS-1. As a consequence, a deep-ocean thermocline develops due to constrained impact of the relatively colder deep ocean to the intermediate depths. In turn, such a deep-ocean thermocline also contributes to the development of the NPIW-to-NPDW density stratification during HS-1, acting as a positive feedback.

Our modelling results provide the physical paleoceanographic mechanisms to explain earlier hypotheses that postulates a stratification development between the NPIW and NPDW during HS-1, as shown in Fig. 1c. In these marine proxy studies, the NW Pacific ventilation age decreased at intermediate depths ${ }^{15,50}$, while it showed insignificant rejuvenation in the deep ocean during HS- $1^{15,25}$. Here, our modelling results suggest that this is attributed to a physical control of the enhanced surface-tointermediate ocean ventilation while the enhanced intermediateto-deep ocean stratification during HS-1.

On a broader scale, our modelling findings have implications for scenarios of the North Pacific deep-ocean $\mathrm{CO}_{2}$ release during the last deglaciation, by showing constrained NPDW formation in response to the AMOC off-mode in HS-1. The inferred physical changes in the configuration of the North Pacific intermediate ocean overturning would significantly enhance and prolong any existing isolation of glacial Pacific deep waters and foster the persistence of a deep pool of sequestered carbon, which was ultimately released from the ocean to atmosphere in other locations ${ }^{12,51}$. As we hypothesize that NPIW and NPDW salinities are key factors in controlling the deglacial ocean ventilation, paleo-salinity reconstructions in future proxy studies would be desirable to further develop the understanding of the physical determinants of the Pacific deep-ocean stratification and carbon pool evolution, in particular during past deglacial warming episodes.

\section{Methods}

Earth System Model MPI-ESM. In this study, we use the fully coupled MaxPlank-Institute Earth System Model (MPI-ESM, version 1.2.00p4) ${ }^{27}$. It employs the atmospheric model ECHAM $6^{52}$ with the land surface component JSBACH ${ }^{53}$ at T63 resolution $\left(1.875^{\circ} \times 1.875^{\circ}\right)$ and 47 vertical layers. In addition, the MPI-ESM uses Max-Plank-Institute Ocean Model (MPIOM) ${ }^{54}$ as the ocean component. It has the GR15 $\left(\sim 1.4^{\circ} \times 0.8^{\circ}\right)$ horizontal resolution and 40 uneven vertical layers, and applies the sea ice dynamics of viscous-plastic rheology $5^{55}$. The model has been previously used for both glacial and interglacial paleoclimate studies ${ }^{27,56}$ and a comparable model version has been employed for the Coupled Model Intercomparison Project Phase 5 (CMIP5) ${ }^{57}$. 
Experimental design. Before simulating the HS-1 climate, we firstly conducted an experiment for the LGM conditions to a quasi-equilibrium state. Our LGM experiment simulates for 4000 model years until a quasi-equilibrium state with SST change less than $0.05^{\circ} \mathrm{C}$ per 100 years and no trend in the variability of the AMOC strength. Here, our LGM experiment applies the full set of the Paleoclimate Modelling Intercomparison Project Phase III (PMIP3) experimental setup for the LGM, including the $21 \mathrm{ka}$ astronomical parameters, greenhouse gases, ice sheets and the corresponding lowered sea level (see http://pmip3.lsce.ipsl.fr/ for the details). Our LGM experiment results show a shallower, but relatively stronger AMOC of $\sim 28 \mathrm{~Sv}$, compared to the $\sim 24.5 \mathrm{~Sv}$ AMOC in the PI, control state. On the basis of the LGM ocean, we mimic the HS- 1 climate conditions by applying an 0.8 Sv FWP 58 to the North Atlantic Ice-Rafted Debris belt region $\left(40^{\circ} \mathrm{N}-55^{\circ} \mathrm{N}, 45^{\circ}\right.$ $\left.\mathrm{W}-20^{\circ} \mathrm{W}\right)^{59,60}$. We conduct the FWP experiment for 400 years until a quasiequilibrium states, when both the AMOC and NPIW strengths show insignificant trends, respectively (Fig. 1d, e).

Calculation of AMOC and NPIW strengths. In our experiments, the calculation of AMOC strength refers to the maximum value of the Atlantic Ocean stream function in the upper $200-3000 \mathrm{~m}$ depths and $30^{\circ} \mathrm{N}$ northward ${ }^{46,61}$. In addition, the NPIW (or NPDW) strength is calculated by the maximum value of meridional overturning stream function in the Pacific of $40-70^{\circ} \mathrm{N}, 0-3500 \mathrm{~m}$ depth (Supplementary Fig. 1).

Response of the NW Pacific sea ice to off-mode AMOC. Studies have shown that the response of stronger NPIW formation to a off-mode AMOC is attributed to various mechanisms on the basis of the LGM state $e^{15,18-24}$. In parallel, along with the stronger NPIW formation of HS-1, the NW Pacific are characterized by comparable-to-LGM SSTs in the Okhotsk Sea during HS-1 ${ }^{38,39}$, suggesting uncertainties in sea ice response to the stronger NPIW formation along with the large sea ice coverage under maxima glacial conditions (Supplementary Fig. 10), thus distinct from the modern climate ${ }^{16,17}$. In our modelling results, the sea ice concentration is characterized by relatively lower values in the southern part of the Sea of Okhotsk and the Bering Sea. On the other hand, the sea ice edge in our FWP experiment with $0.8 \mathrm{~Sv}$ is in line with the HS-1 sea ice area indicated by palaeoceanographic evidences ${ }^{62,63}$, as shown in Supplementary Fig. 11.

Independence of NPIW intensification of HS-1 from LGM AMOC. Paleoclimate modelling studies have presented diverse results in term of the AMOC strength of the LGM compared to the PI conditions ${ }^{64,65}$. In this study, our simulation of the LGM climate has the AMOC of $\sim 28 \mathrm{~Sv}$, stronger than the $\sim 24.5 \mathrm{~Sv}$ in the PI control experiment (Supplementary Fig. 1). Here, we also included an experiment with a 0.2 Sv FWP firstly and then a stronger hosing of $0.8 \mathrm{~Sv}$. As shown in the Supplementary Fig. 1e and Supplementary Fig. 9, the 0.2 Sv FWP weakened the AMOC from the LGM $\sim 28$ Sv to a quasi-equilibrium state of $\sim 20 \mathrm{~Sv}$. Here, we use the LGM state (28 Sv AMOC) and LGM with $0.2 \mathrm{~Sv}$ FWP (20 Sv AMOC) as the representatives for the LGM with stronger- and weaker-than-PI AMOC background, respectively. In this new experiment, the NPIW strength showed insignificant change when the AMOC slowed down to the $20 \mathrm{~Sv}$ due to the $0.2 \mathrm{~Sv}$ FWP, compared to the LGM state of $\sim 28 \mathrm{~Sv}$ (Supplementary Fig. 1f and Supplementary Fig. 9b). On the other hand, when the following 0.8 Sv FWP collapsed AMOC to an off mode (less than $5 \mathrm{~Sv}$ ), the NPIW rapidly increased to $\sim 2.8 \mathrm{~Sv}$. Therefore, the NPIW response to the off-mode AMOC based on the LGM state with 0.2 Sv FWP (i.e. the case for the LGM with weaker-than-PI AMOC background) is in line with the NPIW intensification due to the AMOC collapse based on the LGM state of a stronger-than-PI AMOC (Fig. 1d, e and Supplementary Fig. 9b). Accordingly, although based on a single model, our results indicated that the response of the NPIW intensification to the collapsed AMOC during HS-1 is independent from the LGM AMOC background.

Code availability. The MPI-ESM climate model codes are available by a registration at http://www.mpimet.mpg.de/en/science/models/license/, and the scripts used to generate the plots in this paper are available from the corresponding author on request.

\section{Data availability}

All relevant data in this paper have been uploaded to PANGAEA Data Publisher https:// issues.pangaea.de/browse/PDI-19613.

Received: 4 March 2018 Accepted: 22 January 2019

Published online: 08 February 2019

\section{References}

1. Marcott, S. A. et al. Centennial-scale changes in the global carbon cycle during the last deglaciation. Nature 514, 616-619 (2014).
2. Franois, R. et al. Contribution of Southern Ocean surface-water stratification to low atmospheric $\mathrm{CO}_{2}$ concentrations during the last glacial period. Nature 389, 929-935 (1997).

3. McManus, J. F. et al. Collapse and rapid resumption of Atlantic meridional circulation linked to deglacial climate changes. Nature 428, 834-837 (2004).

4. Burke, A. \& Robinson, L. F. The Southern Ocean's role in carbon exchange during the last deglaciation. Science 335, 557-561 (2012).

5. Ronge, T. A. et al. Pushing the boundaries: glacial/interglacial variability of intermediate and deep waters in the southwest Pacific over the last 350,000 years. Paleoceanography 30, 23-38 (2015).

6. Schmittner, A. \& Galbraith, E. D. Glacial greenhouse-gas fluctuations controlled by ocean circulation changes. Nature 456, 373-376 (2008).

7. Galbraith, E. D. \& Jaccard, S. L. Deglacial weakening of the oceanic soft tissue pump: global constraints from sedimentary nitrogen isotopes and oxygenation proxies. Quat. Sci. Rev. 109, 38-48 (2015).

8. Galbraith, E. D. et al. Carbon dioxide release from the North Pacific abyss during the last deglaciation. Nature 449, 890-993 (2007).

9. Jaccard, S. L. \& Galbraith, E. D. Direct ventilation of the North Pacific did not reach the deep ocean during the last deglaciation. Geophys. Res. Lett. 40, 199-203 (2013).

10. Gray, W. R. et al. Deglacial upwelling, productivity and $\mathrm{CO}_{2}$ outgassing in the North Pacific Ocean. Nat. Geosci. 11, 340-344 (2018).

11. Rae, J. W. et al. Deep water formation in the North Pacific and deglacial $\mathrm{CO}_{2}$ rise. Paleoceanography 29, 645-667 (2014).

12. Ronge, T. A. et al. Radiocarbon constraints on the extent and evolution of the South Pacific glacial carbon pool. Nat. Commun. 7, 11487 (2016).

13. Du, J. et al. Flushing of the deep Pacific Ocean and the deglacial rise of atmospheric $\mathrm{CO}_{2}$ concentrations. Nat. Geosci. 11, 749-755 (2018).

14. Okazaki, Y. et al. Deepwater formation in the North Pacific during the last glacial termination. Science 329, 200-204 (2010).

15. Max, L. et al. Pulses of enhanced North Pacific intermediate water ventilation from the Okhotsk Sea and Bering Sea during the last deglaciation. Clim. Past. 10, 591-605 (2014).

16. Talley, L. D. Distribution and formation of North Pacific intermediate water. J. Phys. Oceanogr. 23, 517-537 (1993).

17. Shcherbina, A. Y. et al. Direct observations of North Pacific ventilation: Brine rejection in the Okhotsk Sea. Science 302, 1952-1955 (2003).

18. Keigwin, L. D. Glacial-age hydrography of the far northwest Pacific Ocean. Paleoceanography 13, 323-339 (1998).

19. Ohkushi, K. I. et al. Last Glacial-Holocene change in intermediate-water ventilation in the Northwestern Pacific. Quat. Sci. Rev. 22, 1477-1484 (2003).

20. Katsuki, K. et al. Sea-ice distribution and atmospheric pressure patterns in southwestern Okhotsk Sea since the Last Glacial Maximum. Glob. Planet. Change 72, 99-107 (2010).

21. Lund, D. C. \& Mix, A. C. Millennial-scale deep water oscillations: Reflections of the North Atlantic in the deep Pacific from 10 to $60 \mathrm{ka}$. Paleoceanography 13, 10-19 (1998).

22. Menviel, L. et al. Removing the North Pacific halocline: effects on global climate, ocean circulation and the carbon cycle. Deep Sea Res. Part II: Top. Stud. Oceanogr. 61, 106-113 (2012).

23. Chikamoto, M. O. et al. Variability in North Pacific intermediate and deep water ventilation during Heinrich events in two coupled climate models. Deep Sea Res. Part II: Top. Stud. Oceanogr. 61, 114-126 (2012).

24. Okumura, Y. M. et al. North Pacific climate response to freshwater forcing in the subarctic North Atlantic: oceanic and atmospheric pathways. J. Clim. 22, 1424-1445 (2009).

25. Lund, D. C. et al. Increased ventilation age of the deep northeast Pacific Ocean during the last deglaciation. Nat. Geosci. 4, 771-774 (2011).

26. Lembke-Jene, L. et al. Deglacial variability in Okhotsk Sea intermediate water ventilation and biogeochemistry: Implications for North Pacific nutrient supply and productivity. Quat. Sci. Rev. 160, 116-137 (2017).

27. Klockmann, M. et al. The effect of greenhouse gas concentrations and ice sheets on the glacial AMOC in a coupled climate model. Clim. Past. 12, 1829-1846 (2016)

28. Bradtmiller, L. I. et al. ${ }^{231} \mathrm{~Pa} /{ }^{230} \mathrm{Th}$ evidence for a weakened but persistent Atlantic meridional overturning circulation during Heinrich Stadial 1. Nat. Commun. 5, 5817 (2014).

29. Lippold, J. et al. Deep water provenance and dynamics of the (de)glacial Atlantic meridional overturning circulation. Earth. Planet. Sci. Lett. 445, 68-78 (2016)

30. Duplessy, J. C. et al. AMS ${ }^{14} \mathrm{C}$ study of transient events and of the ventilation rate of the Pacific intermediate water during the last deglaciation. Radiocarbon 31, 493-502 (1989).

31. Rella, S. F. et al. Abrupt changes of intermediate water properties on the northeastern slope of the Bering Sea during the last glacial and deglacial period. Paleoceanography 27, PA3203 (2012).

32. $\mathrm{Wu}, \mathrm{L}$. et al. Global teleconnections in response to a shutdown of the Atlantic meridional overturning circulation. J. Clim. 21, 3002-3019 (2008). 
33. Bazarova, V. B. et al. New pollen records of Late Pleistocene and Holocene changes of environment and climate in the Lower Amur River basin, NE Eurasia. Quat. Int. 179, 9-19 (2008).

34. Mokhova, L. et al. Quantitative biome reconstruction using modern and late Quaternary pollen data from the southern part of the Russian Far East. Quat. Sci. Rev. 28, 2913-2926 (2009).

35. Matsumoto, K. et al. Interior hydrography and circulation of the glacial Pacific Ocean. Quat. Sci. Rev. 21, 1693-1704 (2002).

36. Meyer, V. D. et al. Glacial-to-Holocene evolution of sea surface temperature and surface circulation in the subarctic northwest Pacific and the Western Bering Sea. Paleoceanography 31, 916-927 (2016).

37. Schmittner, A. et al. Large fluctuations of dissolved oxygen in the Indian and Pacific oceans during Dansgaard-Oeschger oscillations caused by variations of North Atlantic Deep Water subduction. Paleoceanography 22, PA3207 (2007).

38. Riethdorf, J. R. et al. Deglacial development of (sub) sea surface temperature and salinity in the subarctic northwest Pacific: Implications for upper-ocean stratification. Paleoceanography 28, 91-104 (2013).

39. Kiefer, T. \& Kienast, M. Patterns of deglacial warming in the Pacific Ocean: a review with emphasis on the time interval of Heinrich event 1. Quat. Sci. Rev. 24, 1063-1081 (2005).

40. Zhang, R. \& Delworth, T. L. Simulated tropical response to a substantial weakening of the Atlantic thermohaline circulation. J. Clim. 18, 1853-1860 (2005).

41. Mikolajewicz, U. et al. Modelling teleconnections between the North Atlantic and North Pacific during the Younger Dryas. Nature 387, 384-387 (1997).

42. Saenko, O. A. et al. The Atlantic-Pacific seesaw. J. Clim. 17, 2033-2038 (2004),

43. Harada, N. et al. Sea surface temperature changes in the Okhotsk Sea and adjacent North Pacific during the last glacial maximum and deglaciation. Deep Sea Res. Part II: Top. Stud. Oceanogr. 61, 93-105 (2012).

44. Praetorius, S. K. et al. North Pacific deglacial hypoxic events linked to abrupt ocean warming. Nature 527, 362-366 (2015).

45. Davies, M. H. et al. The deglacial transition on the southeastern Alaska Margin: meltwater input, sea level rise, marine productivity, and sedimentary anoxia. Paleoceanography 26, PA2223 (2011).

46. Gong, X. et al. Dependence of abrupt Atlantic meridional ocean circulation changes on climate background states. Geophys. Res. Lett. 40, 3698-3704 (2013).

47. Otto-Bliesner, B. L. et al. Last Glacial Maximum ocean thermohaline circulation: PMIP2 model intercomparisons and data constraints. Geophys. Res. Lett. 34, L12706 (2007).

48. Muglia, J. \& Schmittner, A. Glacial Atlantic overturning increased by wind stress in climate models. Geophys. Res. Lett. 42, 9862-9868 (2015).

49. Muglia, J. et al. Weak overturning circulation and high Southern Ocean nutrient utilization maximized glacial ocean carbon. Earth. Planet. Sci. Lett. 496, 47-56 (2018).

50. Kühn, H. et al. Laminated sediments in the Bering Sea reveal atmospheric teleconnections to Greenland climate on millennial to decadal timescales during the last deglaciation. Clim. Past. 10, 2215-2236 (2014).

51. Herguera, J. C. et al. Evidence for a bathyal front at 2000-M depth in the glacial Pacific, based on a depth transect on Ontong Java Plateau. Paleoceanography 7, 273-288 (1992).

52. Stevens, B. et al. Atmospheric component of the MPI-M Earth System Model: ECHAM6. J. Adv. Model. Earth Syst. 5, 146-172 (2013).

53. Reick, C. H. et al. Representation of natural and anthropogenic land cover change in MPI-ESM. J. Adv. Model. Earth Syst. 5, 459-482 (2013).

54. Marsland, S. J. et al. The Max-Planck-Institute global ocean/sea ice model with orthogonal curvilinear coordinates. Ocean Model. 5, 91-127 (2003).

55. Hibler, W. D. III Dynamic thermodynamic sea ice model. J. Phys. Oceanogr. 9, 815-846 (1979).

56. Shi, X. \& Lohmann, G. Simulated response of the mid-Holocene Atlantic meridional overturning circulation in ECHAM6-FESOM/MPIOM. J. Geophys. Res.: Oceans 121, 6444-6469 (2016).

57. Giorgetta, M. A. et al. Climate and carbon cycle changes from 1850 to 2100 in MPI-ESM simulations for the Coupled Model Intercomparison Project phase 5. J. Adv. Model. Earth Syst. 5, 572-597 (2013).

58. Ganopolski, A. \& Rahmstorf, S. Rapid changes of glacial climate simulated in a coupled climate model. Nature 409, 153-158 (2001).

59. Zhao, M. et al. Molecular stratigraphy of cores off northwest Africa: sea-surface temperature history over the last $80 \mathrm{Ka}$. Paleoceanography 10, 661-675 (1995).
60. Hemming, S. R. Heinrich events: massive late Pleistocene detritus layers of the North Atlantic and their global climate imprint. Rev. Geophys. 42, RG1005 (2004).

61. Gong, X. et al. Higher Laurentide and Greenland ice sheets strengthen the North Atlantic ocean circulation. Clim. Dyn. 45, 139-150 (2015).

62. Max, L. et al. Sea surface temperature variability and sea-ice extent in the subarctic northwest Pacific during the past 15,000 years. Paleoceanogr. Paleoclimatology 27, PA3213 (2012).

63. Méheust, M. et al. Sea-ice variability in the subarctic North Pacific and adjacent Bering Sea during the past 25 ka: new insights from IP 25 and Uk'37 proxy records. Arktos 4, 1-19 (2018).

64. Schmittner, A. \& Somes, C. J. Complementary constraints from carbon $\left({ }^{13} \mathrm{C}\right)$ and nitrogen $\left({ }^{15} \mathrm{~N}\right)$ isotopes on the glacial ocean's soft-tissue biological pump. Paleoceanogr. Paleoclimatology 31, 669-693 (2016).

65. Kurahashi-Nakamura, T. et al. Dynamical reconstruction of the global ocean state during the Last Glacial Maximum. Paleoceanography 32, 326-350 (2017).

\section{Acknowledgements}

We thank AWI colleagues Lars Max and Juliane Müller for helpful discussions, and Christian Stepanek, Xu Zhang and AWI computing centre for technical support. This work was funded through German BMBF grants PalMod (No. 01LP1504A), SIGEPAX (No. 03F0704A) and NOPAWAC (No. 03F0785A). X.G. thanks the International Project of Global Change and Ocean-Atmosphere Interaction (No. GASIGEOGE04), NSFC funding No. 41476056, 41776061 and U1606401, and MSEG funding No MGQNLM201703. G.L. and R.T. acknowledge funding by the Helmholtz national REKLIM initiative.

\section{Author contributions}

All authors conceived the study. X.G., G.K. and G.L. designed the modelling simulations; X.G. performed the model simulations. X.G., G.K. and G.L. analysed the model results. X.G., L.L.J., G.L., R.T., J.J.Z. and X.F.S. discussed the model-data intercomparison. X.G., L.L.J. G.L. and G.K. led the write up of the manuscript. All authors interpreted the results and contributed to the final version of the manuscript.

\section{Additional information}

Supplementary Information accompanies this paper at https://doi.org/10.1038/s41467019-08606-2.

Competing interests: The authors declare no competing interests.

Reprints and permission information is available online at http://npg.nature.com/ reprintsandpermissions/

Journal peer review information: Nature Communications thanks the anonymous reviewers for their contribution to the peer review of this work. Peer reviewer reports are available

Publisher's note: Springer Nature remains neutral with regard to jurisdictional claims in published maps and institutional affiliations.

\section{(i)}

Open Access This article is licensed under a Creative Commons Attribution 4.0 International License, which permits use, sharing, adaptation, distribution and reproduction in any medium or format, as long as you give appropriate credit to the original author(s) and the source, provide a link to the Creative Commons license, and indicate if changes were made. The images or other third party material in this article are included in the article's Creative Commons license, unless indicated otherwise in a credit line to the material. If material is not included in the article's Creative Commons license and your intended use is not permitted by statutory regulation or exceeds the permitted use, you will need to obtain permission directly from the copyright holder. To view a copy of this license, visit http://creativecommons.org/ licenses/by/4.0/.

(C) The Author(s) 2019 